\title{
Greece's Trade With The Balkan Countries: Is It Too Little?
}

\author{
Dionysios Chionis \\ University of Thessaly \\ Panagiotis Liargovas \\ University of Thessaly
}

George Zanias

Athens University

\begin{abstract}
In this paper we use a gravity model in order to estimate the magnitude of potential trade flows between Greece and nine Balkan countries. We adopt a two stage approach. At the first stage the coefficients of the gravity model for the implemented trade between Greece and thirty trade partners are estimated by using the method of Seemingly Unrelated Regression (SUR). At the subsequent step, we implement a research exercise by incorporating the estimated parameters to a gravity equation of Greece and the Balkan countries. It appears that Greece is "under-trading" with all the countries in the reference sample. The ratio of actual over potential exports/imports is less than unity in all cases. Under-trading is more pronounced in the case of imports, where the actual value approaches almost two per cent of the potential.
\end{abstract}

- JEL Classifications: F14, F15, F17

- Key Words: Gravity Model, Greece, Balkans

Corresponding address: Dr. Panagiotis Liargovas, University of Thessaly, Department of Economics, 29 Patroclou Str 15235 Vrilisia, Tel.: +30-1-8041854, fax: +30-1-8041854, E-mail: liargova@uth.gr (C)2002-Center for International Economics, Sejong Institution, All Rights Reserved. 


\section{Introduction}

Given its proximity as well as historical and cultural links, the South-East European region represents for Greece an important potential market of great opportunities. At the same time the magnitude of ethnic, political and economic problems that these countries are facing today within both the domestic and the international context, are enormous. This is because the general situation in the Balkan peninsula was very different in 1989 than it is today. In 1989 Bosnia and Herzegovina, Croatia, FYR Macedonia, Slovenia and $F R$ Yugoslavia were united. Bulgaria and Romania were members of the CMEA and Albania was the most closed and isolated economy in Europe. Recent economic upheavals together with the opening of potential new markets have made it difficult for them to achieve a state of steady economic development. The majority of these countries are in a stage of transition towards the establishment of a market economy and the creation of a basis for self-sustained economic and social growth. They have to resolve a wide range of practical, ethnic, ${ }^{1}$ economic, social and related issues.

The importance of international trade in the process of transition and its association with economic growth has received increasing attention. ${ }^{2}$ The opening up of Central and East European markets will boost international trade. The magnitude of these forces as well as the net effects for the trade partners are still debatable. Most of the previous literature focuses on the potential for trade expansion between Central and Eastern European Countries and the $E U$ as a whole. ${ }^{3}$ Country-specific studies have been carried out for Germany, Spain, Ireland and Greece. ${ }^{4}$ More specifically, Dimelis and Gatsios (1995) compare the actual trade flows between Greece and 6 CEECs (Albania, Bulgaria, Romania, Hungary, Poland and Czechoslovakia) with the potential ones, which are derived by using the Baldwin's (1994) gravity model over a total of 17 exporting countries and 20 trading partners for the period 1979-88. They find a larger potential for growth of trade of the three CEECs compared to the three Balkan countries. However, their predictions are not underpinned by rigorous analysis. In particular there is still lack of conclusive evidence regarding the trading potential of the

\footnotetext{
${ }^{1}$ See for example the ethnic problems that FYR Macedonia is faced recently.

${ }^{2}$ The existing literature is huge; for an overview see Vamvakidis (1998).

${ }^{3}$ See Hamilton and Winters (1992), Baldwin (1994), Winters and Wang (1994), Faini and Portes (1995) and Vittas and Mauro (1997).

${ }^{4}$ See Schumacher (1997) for the case of Germany, Martin and Gual (1994) for the case of Spain, Brulhart and Kelly (2000) for the case of Ireland and Dimelis and Gatsios (1995) for the case of Greece.
} 
Balkan region, a region that is very different compared to Central and Eastern Europe. Our work is a contribution to filling this gap.

From the empirical point of view the methodology adopted in this paper offers a way-out to the lack of historical data. By developing a SUR gravity model and by adopting estimates of the parameters on bilateral trade, we differentiate our study from others and we get a better idea of which of the proposed determinants are actually most likely to affect the bilateral trade in this area. In this sense we also make an empirical contribution.

Greece, as member of the European Union represents, for Balkan countries in transition, an important Western partner who can assist them in their transformation process to market based economies. Therefore, economic cooperation and trade integration between Greece and the Balkan countries can be mutually

Table 1. Growth rates of Greek-Balkan trade

\begin{tabular}{|c|c|c|c|c|c|c|c|c|}
\hline Rates of exports & 19911992 & 1993 & 19941995 & 1996 & 1997 & 1998 & 1999 & 1991-99 \\
\hline Romania & $65 \% \quad 32 \%$ & $0 \%$ & $11 \% \quad 84 \%$ & $1 \%$ & $15 \%$ & $24 \%$ & $9 \%$ & $27 \%$ \\
\hline Bulgaria & $91 \% \quad 99 \%$ & $118 \%$ & $44 \%$ & $-27 \%$ & $16 \%$ & $49 \%$ & $-4 \%$ & $43 \%$ \\
\hline Albania & $-21 \% 254 \%$ & $268 \%$ & $79 \% \quad 17 \%$ & $29 \%$ & $-12 \%$ & $-17 \%$ & $18 \%$ & $68 \%$ \\
\hline FYROM & & $965 \%$ & $-89 \% 190 \%$ & $463 \%$ & $33 \%$ & $6 \%$ & $63 \%$ & $233 \%$ \\
\hline Yugoslavia & $2 \%-56 \%$ & $-100 \%$ & & & & & & $-51 \%$ \\
\hline Slovenia & & $481 \%$ & $-26 \% 478 \%$ & $-71 \%$ & $71 \%$ & $29 \%$ & $1 \%$ & $138 \%$ \\
\hline Croatia & & $719 \%$ & $23 \% \quad 39 \%$ & $4 \%$ & $126 \%$ & $-26 \%$ & $43 \%$ & $133 \%$ \\
\hline Turkey & $5 \% \quad 32 \%$ & $34 \%$ & $-2 \% \quad 53 \%$ & $67 \%$ & $39 \%$ & $-14 \%$ & $0 \%$ & $24 \%$ \\
\hline Bosnia-Herzegovina & & $342 \%$ & $-97 \%-53 \%$ & $482 \%$ & $248 \%$ & $63 \%$ & $119 \%$ & $158 \%$ \\
\hline Serbia-Montenegro & & & & $704 \%$ & $36 \%$ & $0 \%$ & $-37 \%$ & $176 \%$ \\
\hline Balkans & $22 \% \quad 25 \%$ & $87 \%$ & $12 \% \quad 32 \%$ & $35 \%$ & $21 \%$ & $7 \%$ & $9 \%$ & $28 \%$ \\
\hline Total Greek exports & $25 \% \quad 19 \%$ & $3 \%$ & $18 \% \quad 11 \%$ & $12 \%$ & $7 \%$ & $-12 \%$ & $20 \%$ & $11 \%$ \\
\hline Rates of in & 19911992 & 1993 & 19941995 & 1996 & 1997 & 1998 & 1999 & 1991-99 \\
\hline Rom & $47 \%-21 \%$ & $13 \%$ & $50 \% \quad 38 \%$ & $12 \%$ & $61 \%$ & $4 \%$ & $10 \%$ & $24 \%$ \\
\hline Bulgaria & $64 \% \quad 15 \%$ & $39 \%$ & $70 \% \quad 45 \%$ & $-20 \%$ & $28 \%$ & $2 \%$ & $-9 \%$ & $26 \%$ \\
\hline Albania & $11 \% \quad 60 \%$ & $2 \%$ & $142 \%$ & $2 \%$ & $13 \%$ & $9 \%$ & $6 \%$ & $27 \%$ \\
\hline FYROM & & $466 \%$ & $-83 \% 194 \%$ & $179 \%$ & $75 \%$ & $7 \%$ & $2 \%$ & $120 \%$ \\
\hline Yugoslavia & $-6 \%-70 \%$ & $-100 \%$ & & & & & & $-59 \%$ \\
\hline Slovenia & & $640 \%$ & $63 \% \quad 36 \%$ & $-8 \%$ & $3 \%$ & $13 \%$ & $-9 \%$ & $105 \%$ \\
\hline Croatia & & $274 \%$ & $-13 \%-4 \%$ & $-23 \%$ & $-29 \%$ & $93 \%$ & $169 \%$ & $67 \%$ \\
\hline Turkey & $34 \%-8 \%$ & $13 \%$ & $30 \% \quad 17 \%$ & $15 \%$ & $45 \%$ & $34 \%$ & $2 \%$ & $20 \%$ \\
\hline Bosnia-Herzegovina & & $1181 \%$ & $-93 \%-40 \%$ & $-58 \%$ & $104 \%$ & $218 \%$ & $42 \%$ & $193 \%$ \\
\hline Serbia-Montenegro & & & & $7316 \%$ & $95 \%$ & $-22 \%$ & $-36 \%$ & $1838 \%$ \\
\hline Balkans & $22 \%-22 \%$ & $25 \%$ & $37 \% \quad 34 \%$ & $6 \%$ & $43 \%$ & $9 \%$ & $-2 \%$ & $17 \%$ \\
\hline Total Greek imports & $25 \% \quad 14 \%$ & $13 \%$ & $3 \% \quad 13 \%$ & $17 \%$ & $8 \%$ & $2 \%$ & $14 \%$ & $12 \%$ \\
\hline
\end{tabular}


beneficial.

The next section of the paper presents some patterns of trade between Greece and the Balkans. Section 3 discuses the underlining theory of gravity model, while section 4 proceeds with the model specification and the results. Estimates are produced for the future trade integration between Greece and the Balkans. Finally the last section offers some conclusions.

\section{Patterns of Trade between Greece and the Balkans}

The first and most important remark regarding trade between Greece and the Balkans has to do with its rapid evolution over time. Table 1 shows the growth rates of both exports and imports of Greece to and from the Balkan countries during the relevant period. For comparison we also present the growth rates of

Table 2. Growth rates of EU-Balkan Trade

\begin{tabular}{|lrrrrrrrr|}
\hline Rates of exports & 1992 & 1993 & 1994 & 1995 & 1996 & 1997 & 1998 & $1991-99$ \\
\hline Romania & $49,8 \%$ & $10,4 \%$ & $15,4 \%$ & $44,0 \%$ & $15,3 \%$ & $1,0 \%$ & $20,4 \%$ & $22,3 \%$ \\
Bulgaria & $18,6 \%$ & $7,0 \%$ & $22,1 \%$ & $27,9 \%$ & $-25,3 \%$ & $-4,4 \%$ & $44,3 \%$ & $12,9 \%$ \\
Albania & $80,4 \%$ & $21,3 \%$ & $8,6 \%$ & $31,7 \%$ & $35,8 \%$ & $-46,9 \%$ & $25,5 \%$ & $22,3 \%$ \\
FYROM & & & $48,9 \%$ & $36,0 \%$ & $-22,3 \%$ & $-18,2 \%$ & $52,8 \%$ & $19,5 \%$ \\
Yugoslavia & $-10,1 \%$ & & & & & & & $-10,1 \%$ \\
Slovenia & & & $21,5 \%$ & $32,7 \%$ & $0,3 \%$ & $4,5 \%$ & $5,6 \%$ & $12,9 \%$ \\
Croatia & & & $44,7 \%$ & $27,9 \%$ & $0,3 \%$ & $9,5 \%$ & $-2,7 \%$ & $15,9 \%$ \\
Turkey & $3,9 \%$ & $27,9 \%$ & $-23,7 \%$ & $59,5 \%$ & $27,8 \%$ & $10,8 \%$ & $2,6 \%$ & $15,5 \%$ \\
Bosnia-Herzegovina & & & $19,4 \%$ & $58,9 \%$ & $218,0 \%$ & $31,3 \%$ & $11,0 \%$ & $67,7 \%$ \\
Serbia-Montenergro & & & $120,9 \%$ & $70,3 \%$ & $417,9 \%$ & $35,5 \%$ & $5,2 \%$ & $129,9 \%$ \\
\hline Balkans & $3,3 \%$ & $11,1 \%$ & $-0,3 \%$ & $44,4 \%$ & $16,6 \%$ & $7,1 \%$ & $7,3 \%$ & $12,8 \%$ \\
\hline Total EU exports & $5,9 \%$ & $-8,5 \%$ & $14,5 \%$ & $22,1 \%$ & $2,7 \%$ & $1,0 \%$ & $6,7 \%$ & $6,3 \%$ \\
\hline Rates of imports & 1992 & 1993 & 1994 & 1995 & 1996 & 1997 & 1998 & $1991-99$ \\
Romania & $4,9 \%$ & $4,5 \%$ & $59,7 \%$ & $34,0 \%$ & $3,4 \%$ & $10,4 \%$ & $12,3 \%$ & $18,5 \%$ \\
Bulgaria & $24,5 \%$ & $-4,5 \%$ & $43,1 \%$ & $41,7 \%$ & $-9,1 \%$ & $7,9 \%$ & $13,4 \%$ & $16,7 \%$ \\
Albania & $-14,9 \%$ & $29,7 \%$ & $54,2 \%$ & $37,2 \%$ & $27,1 \%$ & $-14,3 \%$ & $13,1 \%$ & $18,9 \%$ \\
FYROM & & & $108,7 \%$ & $19,1 \%$ & $-24,7 \%$ & $-11,1 \%$ & $37,1 \%$ & $25,8 \%$ \\
Yugoslavia & $-10,3 \%$ & $-100,0 \%$ & & & & & & $-55,2 \%$ \\
Slovenia & & & $20,9 \%$ & $24,7 \%$ & $-2,1 \%$ & $-3,0 \%$ & $10,0 \%$ & $10,1 \%$ \\
Croatia & & & $14,1 \%$ & $6,7 \%$ & $-10,8 \%$ & $-8,0 \%$ & $8,6 \%$ & $2,1 \%$ \\
Turkey & $8,1 \%$ & $-8,3 \%$ & $16,6 \%$ & $26,3 \%$ & $4,9 \%$ & $6,8 \%$ & $17,9 \%$ & $10,3 \%$ \\
Bosnia-Herzegovina & & & $-55,6 \%$ & $100,0 \%$ & $181,3 \%$ & $105,6 \%$ & $197,3 \%$ & $105,7 \%$ \\
Serbia-Montenergro & & & $66,7 \%$ & $720,0 \%$ & $1102,4 \%$ & $108,7 \%$ & $-73,8 \%$ & $384,8 \%$ \\
\hline Balkans & $-0,2 \%$ & $-16,6 \%$ & $25,8 \%$ & $26,4 \%$ & $1,8 \%$ & $6,0 \%$ & $12,9 \%$ & $8,0 \%$ \\
\hline Total EU imports & $4,2 \%$ & $-15,1 \%$ & $13,7 \%$ & $20,6 \%$ & $0,9 \%$ & $2,3 \%$ & $10,7 \%$ & $5,3 \%$ \\
\hline Source & & & & & & & &
\end{tabular}

Source: IMF, Direction of trade statistics. 
Table 3. Greek and EU trade with the Balkan countries

\begin{tabular}{|c|c|c|c|c|c|c|c|}
\hline \multicolumn{8}{|c|}{ a. Greece-Balkans (million drachmas) } \\
\hline & $\mathrm{X}$ & $\mathrm{M}$ & $\mathrm{X}-\mathrm{M}$ & $\mathrm{X} / \mathrm{M}(\%)$ & $\mathrm{RX}$ & RM & $\mathrm{R}$ \\
\hline 1990 & 67.349 & 97.379 & -30.029 & $69,2 \%$ & $5,3 \%$ & $3,1 \%$ & $3,7 \%$ \\
\hline 1991 & 82.029 & 119.181 & -37.152 & $68,8 \%$ & $5,2 \%$ & $3,0 \%$ & $3,7 \%$ \\
\hline 1992 & 102.915 & 93.198 & 9.717 & $110,4 \%$ & $5,5 \%$ & $2,1 \%$ & $3,1 \%$ \\
\hline 1993 & 192.780 & 116.626 & 76.154 & $165,3 \%$ & $10,0 \%$ & $2,3 \%$ & $4,4 \%$ \\
\hline 1994 & 215.734 & 159.788 & 55.947 & $135,0 \%$ & $9,4 \%$ & $3,1 \%$ & $5,0 \%$ \\
\hline 1995 & 285.724 & 214.592 & 71.132 & $133,1 \%$ & $11,2 \%$ & $3,6 \%$ & $5,9 \%$ \\
\hline 1996 & 384.534 & 226.613 & 157.921 & $169,7 \%$ & $13,5 \%$ & $3,3 \%$ & $6,3 \%$ \\
\hline 1997 & 466.979 & 323.573 & 143.405 & $144,3 \%$ & $15,3 \%$ & $4,4 \%$ & $7,5 \%$ \\
\hline 1998 & 498.096 & 352.505 & 145.591 & $141,3 \%$ & $18,6 \%$ & $4,6 \%$ & $8,3 \%$ \\
\hline 1999 & 542.971 & 346.739 & 196.232 & $156,6 \%$ & $16,9 \%$ & $4,0 \%$ & $7,5 \%$ \\
\hline \multicolumn{8}{|c|}{ b. EU-Balkans (millions US Dollars) } \\
\hline & $\mathrm{X}$ & $\mathrm{M}$ & $\mathrm{X}-\mathrm{M}$ & $\mathrm{X} / \mathrm{M}(\%)$ & SX & SM & $\mathrm{S}$ \\
\hline 1991 & 23.559 & 21.237 & 2.322 & $110,9 \%$ & $1,6 \%$ & $1,3 \%$ & $1,5 \%$ \\
\hline 1992 & 24.334 & 21.202 & 3.132 & $114,8 \%$ & $1,5 \%$ & $1,3 \%$ & $1,4 \%$ \\
\hline 1993 & 27.026 & 17.692 & 9.334 & $152,8 \%$ & $1,9 \%$ & $1,3 \%$ & $1,6 \%$ \\
\hline 1994 & 26.943 & 22.252 & 4.691 & $121,1 \%$ & $1,6 \%$ & $1,4 \%$ & $1,5 \%$ \\
\hline 1995 & 38.893 & 28.117 & 10.776 & $138,3 \%$ & $1,9 \%$ & $1,5 \%$ & $1,7 \%$ \\
\hline 1996 & 45.351 & 28.632 & 16.719 & $158,4 \%$ & $2,2 \%$ & $1,5 \%$ & $1,8 \%$ \\
\hline 1997 & 48.585 & 30.339 & 18.246 & $160,1 \%$ & $2,3 \%$ & $1,5 \%$ & $1,9 \%$ \\
\hline 1998 & 45.330 & 34.240 & 11.090 & $132,4 \%$ & $2,0 \%$ & $1,6 \%$ & $1,8 \%$ \\
\hline
\end{tabular}

$\mathrm{X}=$ exports, $\mathrm{M}=$ imports, $\mathrm{R}=$ share in total Greek trade, $\mathrm{S}=$ share in total $\mathrm{EU}$ trade.

Source: NSSG.

both exports and imports of $E U$ to and from the Balkan countries during the period 1991-98 (Table 2).The information in these tables confirms that the Balkan countries represent an increasingly dynamic export market for Greek products. The average annual growth rate of Greek exports to the Balkan region over the period 1990-99 is 28per cent. It far outweighs the average growth rates of total Greek exports of around 11per cent as well as the average growth rate of $E U$ exports to the South and Eastern European (SEE) countries of around 13per cent. ${ }^{5}$ Its importance in the near future is likely to increase as Greek firms, which find it difficult or unprofitable to place their products in the competitive $E U$ markets, will find an easy outlet in the Balkans. Imports are also accelerating fast, but not to the same degree as exports. The average growth rate of Greek imports from the Balkans over the period 1990-99 is 17 per cent. They accelerate faster compared

${ }^{5}$ We use the terms "Balkans" and "SEE countries" equivalently.

${ }^{6}$ Croatia is also important for EU exports, with a share of $10.1 \%$. 
to the average growth rate of total Greek imports of around 12 per cent. For the $E U$ as a whole, the average increase in imports from the Balkan countries was only 8 per cent on average over the period 1991-98. However, it far outweighed the average growth of total $E U$ imports of around 5per cent over the same period.

The significant contribution of the increase in exports to total Greek-Balkan trade is reflected in the exports-to-imports ratio (Table 3). For Greek-Balkan trade this ratio has increased from 69.2 per cent in 1990 to 156.6per cent in 1999 turning a trade deficit with the Balkan countries into a trade surplus, whereas for the EUBalkans trade it increased from 110.9 per cent in 1991 to 132.4 per cent in 1998, increasing its trade surplus with the SEE countries.

Trade integration between Greece and the Balkan countries although increasing is still at very low levels. The Balkan trade accounts for 7.5 per cent of total Greek trade, dominated by the share of exports (16.9 per cent) in 1999. For the EU-SEE trade the corresponding shares are around 2 per cent.

\section{The Gravity Model}

The gravity model has been one of the most popular models in the international trade literature aiming at explaining proportion of bilateral trade flows. Formal theoretical foundations of the gravity model are provided in Anderson (1979), who shows that the gravity models can be derived from expenditure share equations, assuming that commodities are distinguished by place of production; Helpman (1984) and Bergstrand (1985) who demonstrate that the gravity model can be derived from models of trade in differentiated products; and Deardorff (1995), who shows that the gravity model is consistent with the Hecksher-Ohlin model expanded to include transport costs. ${ }^{7}$ In general the model relates bilateral trade from origin $i$ to destination $j$ with economic forces at the flows origin, economic forces at the trade destination and economic forces either aiding or resisting the flows movement from origin to destination. The following speci-fication is proposed: ${ }^{8}$

$$
(\text { Trade })_{l j t}=A Y_{i t}^{\alpha} Y_{j t}^{\beta} \Delta_{l j}^{\gamma} U_{t}
$$

where $Y_{i t}^{\alpha}$ and $Y_{j t}^{\beta}$ stand for purchasing power of country of origin and destination respectively and $\Delta_{l j}^{\gamma}$ denotes the distance between the two countries. $U_{t}$ is an error

\footnotetext{
${ }^{7}$ See also Tinbergen (1962).

${ }^{8}$ See also Frankel et al (1995).
} 
term and A represents the constant term.

Under this framework an exporting country's income can be interpreted as the country's production capacity, while an importing country's income is the country's purchasing power. The above is the reduced form equation resulted from a general equilibrium model of world trade where consumers are assumed to share a Constant Elasticity of Substitution (CES) utility function and producers use an internationally immobile production factor according to a constant elasticity of transformation (CET) production function. For the purpose of the present work we also emphasize the effects of relative prices on trade flows. To this end, we incorporate the nominal exchange rate to the standard gravity model. Finally we follow the lines of Linneman (1966), Anderson (1979) Bergstrand (1985), Summary (1989), Wang-Winters (1991), Hamilton-Winers (1992) and Baldwin (1994) and we use aggregate, instead of industry or branch-level, bilateral trade flows. ${ }^{9}$

Attempting to make inferences about the intra-Balkan trade we have to take into consideration the economic and the political environment characterized by the majorities of the Balkan economies. The post-war economic isolation of the Balkan countries, their distorted pricing structures, their recent transition from central planning to a market economy and the structural breaks observed recently, make it difficult to estimate on the basis of extrapolation from historical levels the magnitude of trade which is likely to prevail between Greece and Balkan countries after full economic liberalization. For this reason we attempt to extrapolate information for trade developments by using as a basis the trade patterns among Greece and a reference group of countries which are assumed to exhibit 'normal' trade relationships. Consequently, in order to estimate the trade potential between Greece and the Balkan countries we adopt a two stage approach. At the first stage we estimate the gravity coefficients of the implemented trade among Greece and thirty selective trade partners at various years. This set (see Appendix A) consists mainly of countries from EU, Asia, Africa and America and includes both developed and developing countries. This was done in purpose in order to avoid producing results of trade flows between countries with very specific characteristics. The idea behind this method is that the estimated coefficients will manage to incorporate both the effects of favorable trade conditions between

\footnotetext{
${ }^{9} \mathrm{Also}$, our gravity equation is derived from a two country general equilibrium model. As such it is not suitable to apply our gravity model at the industry or branch level unless we have previously derived production functions and utility functions for branch level.
} 
Greece and developed or $E U$ countries but also the effects of unfavorable trade conditions. The inclusion of developed countries only, would not lead to normal results since the cost of trade may be lower due to high levels of infrastructure. Similarly the inclusion of developing countries only, would not reflect normal trade due to the fact that developing country trade is more likely to be affected by various bureaucratic policy distortions. ${ }^{10}$ Across this framework the variety of destinations and origins also ensures that the estimated coefficients pictures out both manufactures driven and resources driven trade.

At the subsequent step, we derive the potential trade volumes by applying the coefficient estimates derived by the reference group to these countries whose potential trade flows are of interest. More specifically, we implement a research exercise by incorporating the estimated parameters to a gravity equation of Greece and the Balkan countries.

\section{Model Specification and Results}

For the purpose of the present work we use cross section-section data to estimate the trade effects and relationships for a particular time period. By keeping the observations of each time period separately we obtain four equations for each specification as following:

$$
\begin{aligned}
& \ln (\text { exports })_{t}=\alpha+\beta_{t t}\left(y_{i t}\right)+\beta_{2 t}\left(y_{G R t}\right)+\beta_{t t}\left(D_{i}\right)+\beta_{l t}\left(e_{i t}\right)+U_{t t} \\
& \ln (\text { imports })_{t}=\alpha+\beta_{t t}\left(y_{i t}\right)+\beta_{2 t}\left(y_{G R t}\right)+\beta_{t t}\left(D_{i}\right)+\beta_{l t}\left(e_{i t}\right)+U_{t t}
\end{aligned}
$$

Where $t=1985,1990,1995,1998$ and $y_{i t}, y_{G R t}$ stand for the logarithmic transformation of per capita GDP of the trade pattern and per capita GDP of Greece respectively. $D_{i}$ denotes the logaritmic transformation of the miles distance between the capital cities, $e_{i t}$ denotes the logarithmic transformation of the

\footnotetext{
${ }^{10} \mathrm{By}$ using this heterogeneous country sample we can also avoid using specific dummy variables, e.g. EU dummy variable etc.

${ }^{11}$ One issue of concern as regards the gravity equation specification is the use of dummy variables. It is true that in many other studies, country or city or regional dummies are introduced to the gravity model to better capture country or city or region specific effects (e.g. Karemera et al. (1999), Coe and Hoffmaister (1998) etc). However, we have not used such dummies here for two reasons: first, if we introduce them to the analysis of the present paper, we will not be able to obtain the estimated value of trade for Balkan countries since their country dummies are not known. Second in an effort to provide an alternative specification with the use of an " $E U$ " dummy variable which might reflect the case of Bulgaria and Romania when they will become $E U$ member states, we did not get significant results. ${ }^{12} \mathrm{~A}$ similar approach is found in Wei (1996), Bougheas et al.(1999).
} 
Table 4. Gravity model for twenty nine countries and Greece

\begin{tabular}{|lcc|}
\hline & \multicolumn{2}{c|}{ ESTIMATED COEFFICIENTS } \\
\hline Regressors & EXPORTS REGRESSION & IMPORTS REGRESSION \\
\hline \multirow{2}{*}{ Constant } & 0.853 & -0.863 \\
& $(0.225)$ & $(-0.319)$ \\
GDP trade partner & $0.438^{*}$ & $0.479^{*}$ \\
& $(2.21)$ & $(4.2)$ \\
GDP Greece & $0.479^{*}$ & $0.692^{*}$ \\
& $(2.08)$ & $(3.74)$ \\
DISTANCE & $-0.526^{*}$ & -0.17 \\
& $(-2.003)$ & $(1.94)$ \\
EX-RATE & -0.001 & 0.04 \\
R & $(-0.36)$ & $(1.2)$ \\
F-statistic & 0.85 & 0.96 \\
& 31.2 & 30.8 \\
\end{tabular}

The t-stat in parentheses estimated using heteroscedasticity robust errors.

*denotes statistical significance at $5 \%$

exchange rate expressed in terms of $U S D$ and $U_{\imath \tau}$ is the error term. ${ }^{11}$

We estimate these four cross section equations jointly using the method of Seemingly Unrelated Regression $(S U R)^{12}$. In this way we allow for correlation between the error terms since, for example, the errors of Greece-Germany may be related with the errors of Greece-France (see in the appendix the correlation coefficients across the SUR residuals). Furthermore, in order to improve the efficiency we constrain all coefficients (except the constant term) to be equal across time.

The data of international trade is withdrawn from the Greek National Statistical Service for the years 1985, 1990, 1995,1998. By using four specific years since 1985 we lower the influence of outliers in the time dimension and we avoid the choice of a "wrong" base year. ${ }^{13}$ Therefore the extracted elasticities will better reflect normal Greek trade. Also, the comparative advantage of the estimation method of Seemingly Unrelated Regressions $(S U R)$ is related with the ability to combine the relevant information for different time periods. ${ }^{14}$ Especially in our

\footnotetext{
${ }^{13}$ Furthermore, for comparison purposes we also conducted one computation based on four different cross section regressions and then we estimated the potential trade by taking the average of the four coefficients. The derived ratios between actual and potential do not differ very much with the existing ones

${ }^{14}$ Since there are no available historical data for the Balkan countries, not even input-output matrices, our proposed method for adopting the estimated parameters is the only remaining method.
} 
case where the coefficient have been constrained to be equal across the four different time periods. The data of GDP per capita and real GDP per capita in constant dollars (international prices, base year 1985) is withdrawn from the International Financial Statistics of $I M F^{15}$. The exchange rate data is also taken from the International Financial Statistics of $I M F$ at various years. Since we take the logarithmic transformation the zeros have been substituted be the number 0.001 .

Taking into account the existence of heteroscedasticity (using the Bruce Pagan test we can reject the null hypothesis of no-heteroscedasticity at any significance level) we compute regression standard errors and covariance matrix allowing thus for heteroscedasticity and serial correlation of the residuals (robust errors).

One can argue that the use of pooled data into a time series and cross sectional framework could derive more sensible estimated coefficients. In this case we should also take into consideration that two of the explanatory variables, the distance variable and the per capita GDP of Greece have one dimension and consequently the panel techniques cannot derive sensible estimators.

We report the results using exports from Greece to third country (Table 4) and imports from third country to Greece. In line with other studies we find that the basic gravity model has a high explanatory power given the high values of $R^{2}$ for the SUR model. When considering a set of seemingly unrelated regression equations the standard $R^{2}$ is an unambiguous measure. One possibility for a measure of a goodness of fit is the $R^{2}$ obtained by applying least squares to the whole system (see Judge et al. (1985)). The estimated $R^{2}$ varies from 85-96per cent across the three specifications. Among the three SUR specifications, the smallest statistic used is $\mathrm{F}=27.4$ which significantly exceeds the critical value of $\mathrm{F}(12,60)=3.5$ at the 1 per cent level.

According to the derived results the estimated coefficients on GDP in all cases are significant at the 5 per cent level, have the expected sign ${ }^{16}$ and are quite close to those found in other studies. An increase in the GDP of Greece by one unit leads to an increase in Greek exports by 0.479 and Greek imports by 0.69 . With

\footnotetext{
${ }^{15}$ We derived similar results by using, instead of real GDP per capita, GDP in dollar terms.

${ }^{16} \mathrm{We}$ also attempted to derive the coefficients of the gravity equation by using the cross section data, $O L S$, at a particular time. There exist two sorts of problems related with this proposed method. The first one is associated with the quality of the estimated coefficients since most of them are statistical insignificant. Constraining the coefficients of the SUR system to be equal across time we gain efficiency. The second problem is associated with the magnitude of each coefficient which differs across the examined periods, creating selection problems. In any case the $O L S$ estimations are available from the authors upon request.
} 
the same token, an increase in the GDP of the trade partner increases Greek exports by 0.438 and imports by 0.48 respectively. The one unit increase in the GDP of the trade partner's results in 0.479 increase of Greek imports while the unit of trade partners GDP increases the Greek imports by 0.692 . By contrast the derived coefficients for exchange rates are not statistical significant. One potential explanation relates to the irresponsiveness of international trade to the exchange rate fluctuations. The important issue which must be considered in the trade flowsexchange rate relationship is the time needed for trade flows to be adjusted to nominal exchange rate changes due to existence of sunk cost. The variable distance enters significantly only into the exports equation while constant is insignificant in both equations. It is also striking the insignificant value of the distance variable in the imports regression equation. A possible explanation is related to the geographical distance of Greece from the main import partners (Japan, USA). According to the trade data of 1998, approximately 20 per cent of Greek imports come from destinations being in average 3,452 air-miles.

At the next stage we estimate the potential trade flows between Greece and the

Table 5. Estimated Potential Imports (in million USD)

\begin{tabular}{|lrcc|}
\hline Countries & Actual & Estimated & Actual/Estimated (\%) \\
\hline Romania & 187.354 & $6,662.77$ & $2.8 \%$ \\
Bulgaria & 312.936 & $6,393.52$ & $5.0 \%$ \\
Albania & 33.975 & $2,995.60$ & $1.2 \%$ \\
FYROM & 53.281 & $4,075.71$ & $1.3 \%$ \\
Yugoslavia & 53.899 & $3,144.53$ & $1.7 \%$ \\
Slovenia & 19.959 & $5,624.35$ & $0.3 \%$ \\
Croatia & 27.474 & $5,675.65$ & $0.4 \%$ \\
Turkey & 327.340 & $1,044.80$ & $3.0 \%$ \\
Bosnia-Herzegovina & 3.199 & $2,665.90$ & $0.1 \%$ \\
\hline
\end{tabular}

Table 6. Estimated Potential Exports (in million USD)

\begin{tabular}{|lrrc|}
\hline Countries & Actual & Estimated & Actual/Estimated (\%) \\
\hline Romania & 187.35 & 299.5 & $62.0 \%$ \\
Bulgaria & 313.07 & 594.87 & $52.0 \%$ \\
Albania & 198.54 & 302.24 & $56.6 \%$ \\
FYROM & 381.04 & 408.35 & $93.3 \%$ \\
Yugoslavia & 11.99 & 268.48 & $4.4 \%$ \\
Slovenia & 19.67 & 391.40 & $5.0 \%$ \\
Croatia & 23.11 & 465.80 & $4.9 \%$ \\
Turkey & 300.60 & 421.00 & $7.1 \%$ \\
Bosnia-Herzegovina & 11.99 & 241.62 & $4.9 \%$ \\
\hline
\end{tabular}


selected Balkan Countries by using the statistically significant parameter-estimates produced by the gravity equation of the trade implemented between Greece and thirty trade partners. In Tables 5 and 6, we compare the trade volumes predicted on the basis of the gravity coefficients with actual flows for 1998 for the reference group. This gives us an indication of trade flows which would have been prevailed between Greece and the selected Balkan countries had the latter been fully market oriented economies.

It appears that Greece is "under-trading" with all countries in the reference sample. The ratio of actual over potential exports/imports is less than unity in all cases. Under-trading is more pronounced in the case of imports, where the actual is around 2 per cent of the potential. It is also striking that trade with Bulgaria albeit still accounting for the largest share, is well below the predicted normal level.

\section{Conclusions}

The purpose of this study was to use a gravity model in order to estimate the normal or potential volume of trade between Greece and the South Eastern European countries, which can then be compared to observed trade flows. A preliminary analysis showed that the current level of trade integration between Greece and the Balkan countries as well as $E U$ and the Balkan countries is at relatively low levels. However, Greek exports to the Balkans outperform Greek imports from the Balkans. This is also true for the $E U$ exports, but not to the same degree as in the case of Greek exports. By using the method of Seemingly Unrelated Regression, we found that there is a lot of potentiality as regards Greece's trade with the Balkans. The ratio of actual over potential exports/imports is less than unity in all cases. Under-trading is more pronounced in the case of imports, where the actual is on average 2 per cent of the potential. Given the very low levels of Greek imports from the Balkans this result is not surprising.

\section{Acknowledgement}

We thank two anonymous referees for useful comments and suggestions made on a previous version of this paper. We have the responsibility of all remaining errors.

Date accepted: August 2001 


\section{References}

Anderson, James (1979), “A Theoretical Foundation of the Gravity Equation," American Economic Review, 69, 106-16.

Baldwin, Richard (1994), Towards an Integrated Europe, London: Center for Economic Policy Research.

Bergstrand J (1985), “The Gravity Equation in International Trade: Some Microeconomic Foundations and Empirical Evidence," The Review of Economics and Statistics, 67, 474-481.

Bougheas S., P. Demetriades and E. Morgenroth (1999), "Infrastructure, transport costs and trade, " Journal of International Economics 47, 169-189.

Brulhart Marius and Mary Kelly (1999), "Ireland's Trading Potential with Central and Eastern European Countries: A Gravity Study," The Economic and Social Review; 30(2), 159-174.

Chionis D. and R. MacDonald (2001), "The Hysteretic Effects on the Real Exchange Rates," International Review of Applied Economics, 16(4), forthcoming.

Coe David and Alexander Hoffmaister (1998) "North-South Trade: Is Africa Unusual?" IMF Working Paper, WP/98/94, Washington D.C.

Deardorf Allam (1985), "Determinants of Bilateral Trade: Does Gravity Work in a Neoclassical World? " NBER Working Paper No.5377 (Cambridge, Massachusetts: National Bureau of Economic Research).

Dimelis S. and K. Gatsios (1995), "Trade with Central and eastern Europe: The Case of Greece", in European Union Trade with Eastern Europe. Adjustment and Opportunities, Riacardo Faini and Richard Portes (eds), Center for Economic Policy Research, London.

Faini Riccardo and Richard Portes (eds) (1995), European Union Trade with Eastern Europe: Adjustment and Opportunities, London: CEPR.

Frankel J., E. Stein,and S. Wei (1995) "Trading Blocks and the Americas: The Natural the Unnatural, and the Super-Natural," Journal of Development Economics 47; 61-95.

Hamilton, C.B. and Winters L.A. (1992) "Opening up International Trade with Eastern Europe, "Economic Policy 14, 77-116.

Helpman Elhanan (1984) "Increasing Returns, Imperfect Markets, and Trade Theory," in Ronald W. Jones and Peter Kenen (Eds) Handbook of International Economics, Vol.1 (Amserdam: North-Holland), pp. 325-65.

Judge G. W Griffits R. Hill H. Lutkepohl T. Lee (1985), The Theory and Practice of Econometrics, Willey, New York.

Karemera David, Wilbur I. Smith, Kalu Ojah and John A. Cole (1999), “A Gravity Model Analysis of the Benefits of Economic Integration in the Pacific Rim," Journal of Economic Integration 14(3), 347-367.

Linneman, Hans (1966), An Econometric Study of International Trade Flows, Amsterdam: North Holland Publishing. 
Hamilton, Carl and Winters, Alan (1992), "Opening up Trade with Eastern Europe, " Economic Policy 14, 77-116.

Martin, Carmela and Gual Jordi (1994), "Trade and Foreign Direct Investment with Central and Eastern Europe; Its Impact on Spain," CEPR Discussion Paper, No. 1006.

Summary, Rebecca (1989), "A Political Economic Model of U.S. Bilateral Trade," The Review of Economics and Statistics, 71(1), 179-92.

Schumacher Dieter (1997), "Impact on German Trade of Increased Division of Labour with Eastern Europe," in Stanley W. Black (Ed), Europe's Economy Looks East, Cambridge University Press.

Tinbergen Jan (1962), Suggestions for an International Economic Policy, New York: The Twentieth Century Fund.

Uvalic Milica (2000), "Regional Cooperation in South-Eastern Europe," Halki Southeast European Network on Economic Reconstruction.

Vamvakidis Athanasios (1998), "Regional Integration and Economic Growth", The World Bank Economic Review 12(2), 251-70.

Vittas, Hari and Paolo Mauro (1997) "Potential Trade with Core and Periphery. Industry Differences in Trade Patterns," in Stanley W. Black (ed), Europe's Economy Looks East, Cambridge University Press.

Wang Z.K. and Winters L.A. (1991), The Trading Potential of Eastern Europe, CEPR Discussion Paper Series, (610).

Winters, Alan and Wang Z.K. (1994), Eastern Europe's International Trade, Manchester University Press.

Wei S.-J. (1996), "Intra-national versus international trade: how stubborn are nations in global integration?" NBER working Paper No. 5531

\section{Appendix A}

\section{A. Countries Used for the SUR estimations}

Argentina, Austria, Belgium-Luxembourg, Brazil, Canada, Switzerland, Cyprus, Germany, Denmark, Egypt, Spain, Finland, France, UK, USA, Ireland, Iran, Israel, Italy, Japan, N. Korea, Morocco, Netherlands, Norway, Portugal, Sweden, Tunis, Turkey and USA.

\section{B. Residuals Correlation Matrix}

This is a square table with co-variances on and below the diagonal and correlation above the diagonals 
CovariancelCorrelation Matrix of Export Residuals

\begin{tabular}{|lcrrr|}
\hline & EX98 & \multicolumn{1}{c}{ EX90 } & \multicolumn{1}{c|}{ EX95 } & \multicolumn{1}{c|}{ EX98 } \\
\hline EX98 & 2.444191895616 & 0.0976020578 & 0.8282898656 & 0.9986305325 \\
EX90 & 0.243078762099 & 2.537702946453 & 0.2483387653 & 0.1067524538 \\
EX95 & 1.849273506889 & 0.564957866255 & 2.039399463771 & 0.8303436721 \\
EX98 & 2.412631072733 & 0.262794750327 & 1.832430271048 & 2.388013917975 \\
\hline
\end{tabular}

CovariancelCorrelation Matrix of Imports Residuals

\begin{tabular}{|rrrrr|}
\hline & \multicolumn{1}{c}{ IM98 } & \multicolumn{1}{c}{ IM90 } & \multicolumn{1}{c|}{ IM95 } & \multicolumn{1}{c|}{ IM98 } \\
\hline IM98 & 1.928204617018 & 0.9998430267 & 0.9997652287 & 0.9997429392 \\
IM90 & 1.946856815740 & 1.966306710622 & 0.9999651423 & 0.9999377992 \\
IM95 & 1.951196013347 & 1.970773911233 & 1.975388973341 & 0.9999843912 \\
IM98 & 1.955252884096 & 1.974861515899 & 1.979509380498 & 1.983700308174 \\
\hline
\end{tabular}

